\title{
TRABALHO POR PROJETO: UTILIZAÇÃO DE UMA HORTA ESCOLAR PARA O ENSSINO E APRENDIZAGEM DE CIÊNCIAS
}

\author{
PRISCILA TOSCANO LIMA \\ NATÁLIA DIAS \\ MARILENA SOUZA ROSALEN
}

\begin{abstract}
RESUMO
Este trabalho apresenta o desenvolvimento e análise do projeto de horta escolar em uma escola pública estadual de Diadema, como integrante do Programa Institucional de Bolsa de Iniciação à Docência - PIBID, subprojeto de Ciências, da Universidade Federal de São Paulo - UNIFESP. Os objetivos foram: incorporar a horta nas atividades escolares existentes; organizar um plano de ação por meio do qual os alunos pudessem conhecer algumas hortaliças utilizadas na alimentação; verificar a importância do hábito de uma alimentação saudável realizando o cultivo e consumo de produtos livres de agrotóxicos; e sensibilizar os alunos sobre o descarte dos resíduos orgânicos e sua reutilização. Para o alcance dos objetivos, foram feitas várias atividades, como: levantamento de conhecimentos prévios dos educandos por intermédio de questionário; debates a respeito de aspectos da agricultura, alimentação humana e questões específicas referentes ao cultivo de uma horta; pesquisas na internet: "como montar uma horta caseira" (com todas as etapas necessárias); experimento: pigmentos vegetais; estudo da fotossíntese; limpeza e preparação do terreno para o plantio; montagem da composteira; plantio das hortaliças; manutenção semanal da plantação; colheita e consumo dos alimentos oriundos da horta. Como resultado, foi possível a abordagem de questões científicas, de saúde e sociais relacionadas ao cultivo de alimentos. Também foram possíveis a produção e o uso de adubo orgânico, a irrigação por gotejamento e a reutilização de resíduos sólidos orgânicos por meio da compostagem. Palavras-chave: Horta escolar. Ensino de Ciências. Trabalho por projeto.
\end{abstract}




\begin{abstract}
This work presents the development and analysis of the project that occurred during school hours, in a state public school in Diadema, as part of the Institutional Program for the Initiation to Teaching - PIBID, subproject of Sciences, belonging to Federal University of São Paulo - UNIFESP. The objectives were: to incorporate a vegetable garden into existing school activities; Organize a plan of action through which students could meet some vegetables used in food; Check the importance of the habit of a company producing agricultural products and consumption of pesticide products; And sensitize students about the disposal of organic waste and its reuse. In order to achieve the objectives, various activities were carried out, such as: lifting prior knowledge of students through questionnaire; debates about agriculture, human food and specific questions related to the cultivation of a vegetable garden; internet research: "how to set up a home garden" (with all necessary steps); experiment: vegetable pigments; photosynthesis study; cleaning and preparation of the land for planting; preparation of the place and instruments for composting; planting of vegetables; weekly planting maintenance; harvest and consumption of food from the vegetable garden. As a result, it was possible to approach scientific questions about Health and social aspects related to food. In addition, the production and use of organic fertilizer, drip irrigation and reuse of organic solid waste by composting.
\end{abstract}

Key-words: School garden. Teaching of sciences. Work project.

\title{
INTRODUÇÃO
}

Tendo em vista toda a demanda mundial com a preocupação da preservação do meio ambiente e dos prejuízos causados à natureza pelo homem ao longo dos últimos anos, as escolas estão começando a repensar suas atividades pedagógicas e inserindo a Educação Ambiental e práticas sustentáveis no seu projeto pedagógico.

A fim de garantir que tais práticas se unam ao contexto social, econômico, ambiental e sustentável local e global, pesquisas vêm propondo no âmbito educacional projetos que busquem 
a união com a comunidade escolar. Nesta linha, encaixam-se propostas com a construção de hortas escolares, de maneira a oportunizar aos estudantes o desenvolvimento de uma relação direta com o ambiente, possibilitando o cuidado com a terra, valorização dos recursos naturais locais de maneira produtiva e sustentável e ainda interdisciplinar.

Kilpatrick (1967) considera que a estruturação dos projetos deve partir da busca de uma solução para determinado problema, pois isso causa interesse, engajamento, e assim é necessário partir de uma prática ligada ao social, e é necessário pensar um projeto de forma interdisciplinar. Entende-se que, em um projeto de horta, a escola é um agente para promover a educação ambiental, mas também é um local de promoção da educação alimentar, uma vez que é na infância e na adolescência que se afixam atitudes e práticas alimentares complexas, que podem mudar quando os alunos são adultos (TURANO, 1990).

Esses aspectos correspondem ao que os Parâmetros Curriculares Nacionais (PCN) recomendam para esses conteúdos - educação ambiental e alimentar - de que eles sejam tratados como temas transversais de forma interdisciplinar na educação formal. Ou seja, propõe-se que as questões do meio ambiente e de saúde permeiem os objetivos, conteúdos e orientações didáticas em todas as disciplinas (ZUCCHI, 2002).

A união da educação ambiental com a perspectiva dos projetos é uma oportunidade de o aluno aprender no processo de produzir, levantar dúvidas, pesquisar e criar relações que incentivam novas buscas, descobertas, compreensões e reconstruções de conhecimento (PRADO, 2005). No caso, o cultivo de uma horta, implementada por meio de um projeto - permanente - pela comunidade escolar, significa ter na escola um laboratório vivo que permite o desenvolvimento de várias tarefas pedagógicas em educação ambiental e alimentar que une teoria e prática de modo contextualizado, ajudando no processo de ensino e estreitando relações por meio da promoção do trabalho em equipe (MORGADO, 2008).

Gadotti (2003) defende que hortas na escola são como um microcosmos de todo o mundo natural, onde encontramos for- 
mas de vida, recursos de vida, processos de vida, e a partir dele o professor pode (re)conceitualizar nosso currículo escolar. As crianças, em contato com a horta construída, encaram-na como fonte de mistérios, como um sistema de valores da emocionalidade com a Terra: a vida, a morte, a sobrevivência, os valores da paciência, da perseverança, da criatividade, da adaptação, da transformação, da renovação (IDEM, p. 62).

Uma atividade que vai diretamente ao encontro do trabalho com hortas em escolas é a compostagem, uma vez que ela é de fácil viabilização dos resíduos gerados pela própria escola, evitando-se que virem lixo, como acontece com grande parte da comida produzida no mundo. Há perdas desde o plantio, transporte, armazenamento, preparo e restos não consumidos. Com a valorização da própria produção por meio da horta escolar ou hortas caseiras, esse desperdício diminui consideravelmente, pois o tratamento com o alimento e solo é cuidadoso, não existem perdas ou gastos com transportes, o preparo e o consumo são conscientes e os resíduos mínimos produzidos são reutilizáveis de uma forma sustentável por intermédio de compostagem doméstica. Reduzir o desperdício pode mudar a situação dos volumes de resíduos orgânicos e melhorar o panorama do problema da fome e a escassez de alimento.

A compostagem é uma técnica que consiste num processo de reaproveitamento de resíduos orgânicos a partir da atividade de micro-organismos, para a formação de adubo orgânico. A quantidade de resíduos sólidos depositada nos lixos, e por conseguinte nos lixões, poderia ser minimizada se a compostagem fosse aplicada na escola. Principalmente se o bairro onde a comunidade escolar está inserida for um bairro que sofre com o problema de excesso de lixo, prejudicando esgotos, saneamento básico, causando mau cheiro etc. A compostagem é uma maneira simples de reaproveitar o lixo orgânico e minimizar os impactos ambientais e uma boa prática para ensinar e ilustrar conceitos científicos na escola.

Para Costa e Silva (2011), a utilização da compostagem em aulas práticas de Ciências é de extrema relevância, pois pode promover a associação ensino/pesquisa, a interdisciplinaridade 
com outras disciplinas do currículo escolar, até porque este é um método de contextualizar o conteúdo exposto pelo professor com o dia a dia do aluno. Além disso, os discentes tornam-se mais interessados pelas aulas, devido ao despertar de sua curiosidade e caráter investigativo necessários no estudo gerado pelo tema. Esse método é inovador, rompendo as tradicionais aulas expositivas clássicas, buscando-se uma perspectiva de articulação entre a teoria e a prática, ou seja, interagindo mais nas aulas os estudantes têm a oportunidade de aplicar no seu cotidiano o conhecimento construído.

\section{OBJETIVOS}

Este trabalho apresenta o desenvolvimento e a análise do projeto de horta escolar em uma escola pública estadual de Diadema, como integrante do Programa Institucional de Bolsa de Iniciação à Docência - PIBID, subprojeto de Ciências, da Universidade Federal de São Paulo - UNIFESP, que teve como objetivos:

- Incorporar a horta nas atividades escolares existentes;

- Organizar um plano de ação por meio do qual os alunos pudessem conhecer algumas hortaliças utilizadas na alimentação;

- Verificar a importância do hábito de uma alimentação saudável realizando o cultivo e o consumo de produtos livres de agrotóxicos;

- Sensibilizar os alunos sobre o descarte dos resíduos orgânicos e sua reutilização.

\section{PROJETO HORTA ESCOLAR}

O relato do desenvolvimento e análise do projeto é apresentado a partir das seguintes temáticas: 1) Etapa de sensibilização e engajamento; 2) Implantação da horta; 3) A compostagem; 4) Trabalhando a interdisciplinaridade; 5) Prática e ação; 6) Aspectos do trabalho por projetos.

\section{ETAPa de SEnsibilização e engajamento}

É a etapa que se refere a unir forças na escola para a realização do projeto, busca de apoio da gestão, mobilização 
frente ao projeto e organização para envolver os estudantes nas seguintes atividades: identificação do cenário (diagnóstico), como suporte para a implantação do modelo da composteira doméstica; reuniões com a diretora, professores e profissionais responsáveis pela cozinha da escola; discussão sobre a possibilidade da construção de uma horta na escola. E ainda, onde ocorreu a sondagem, o momento de levantamento das concepções prévias dos estudantes, por meio de discussões em sala de aula.

Inicialmente foi preciso sensibilizar os estudantes para a importância de novas atitudes e posturas, em relação à reciclagem de resíduos, desperdício de alimentos, água e energia, separação de resíduos sólidos e reciclagem. Posteriormente, com essas habilidades desenvolvidas foi trabalhada a sustentabilidade no espaço escolar por meio de mobilização dos estudantes envolvidos e participantes do projeto (equipe gestora, bolsistas do PIBID-UNIFESP, funcionários, professores e comunidade) na construção e manutenção de uma horta escolar.

Essas ações foram necessárias porque a horta exige uma flexibilidade de espaço e de tempo. A aula acontecia no canteiro, quando o sol não estava muito forte.

Ensinar e aprender exigem hoje muito mais flexibilidade espaço- temporal, pessoal e de grupo, menos conteúdos fixos e processos mais abertos de pesquisas e de comunicação (MORAN, MASETTO, BEHRENS, 2001, p. 29).

Na mesma direção dessa citação, a sensibilização para as novas práticas foi feita por meio de vídeos, pesquisas, rodas de conversa e campanhas construídas pelos próprios alunos. Essa etapa se fez necessária para incorporar conhecimentos em Educação Ambiental e Sustentabilidade, o que despertou o interesse e o comprometimento dos estudantes. A equipe mostrou-se, então, preparada para um dos passos mais importantes desse projeto: a revitalização e a transformação do espaço físico da escola, para a implantação da horta sustentável. Alguns dos vídeos utilizados para a sensibilização e aprofundamento da aprendizagem foram: 


a) Projeto Horta na Escola $-<$ https://youtu.be/JHCpOAcwHX0>;
b) Educando com a Horta Escolar $-<$ https://youtu.be/
bmzNPFUiyn4 $>$;
c) Solo na Escola - Vermicompostagem $-<$ https://youtu.be/
pRNs3tfyihg $>$;
d) Emater responde - Composteira doméstica - Programa Rio
Grande Rural $-<$ https://youtu.be/JAvRK1dO8AE $>$;
e) Os Caminhos do Lixo - Programa de Educação Ambiental
Compartilhado $-<$ https://youtu.be/rsgYBNX6E_0 $>$.

Tabela 1: Links dos vídeos utilizados para a sensibilização (todos os links de acesso foram conferidos no período de maio/2017 e continuam disponíveis para a visualização no site do YouTube).

\section{IMPLANTAÇÃO DA HORTA}

A área destinada à implantação da horta escolar localizava-se em um espaço do estacionamento dos professores onde servia de depósito para telhas quebradas, acúmulo de lixo e mato crescido. A limpeza e a revitalização do local fizeram-se através do estudo e avaliação inicial das características do solo da área de implantação. Verificou-se que nesse local a horta seria destruída, pois alguns carros de visitantes ficavam estacionados lá. Após essa constatação, um novo local foi escolhido. O novo local ficava ao lado da entrada do portão principal da escola e lateralmente às salas de aula. Enquanto se definia o local, buscou-se suportes teóricos como livros, artigos, revistas especializadas, vídeos, sites, que pudessem servir de auxílio na implantação da horta.

Essa etapa iniciou-se em maio de 2016, com a limpeza do local, pois a terra não estava apropriada para o plantio, e teve que ser aerada manualmente pelos alunos e cooperadores do projeto. Foram utilizadas enxadas, pás e ferramentas improvisadas, pois não tivemos muitos recursos financeiros para a compra de materiais necessários para a construção da horta. Os canteiros, 
depois de delimitados, foram demarcados por aproximadamente 600 tijolos. Após a demarcação, foram feitas as covas para a semeadura e instalado o sistema de irrigação. A irrigação da horta foi realizada por gotejamento por garrafa PET, sendo usados produtos de baixo custo e materiais reciclados para a construção desse sistema.

As minhocas utilizadas foram doadas por amigos pessoais dos educadores que trabalhavam no projeto. As sementes e mudas foram plantadas pelos alunos, orientados pela professora e bolsistas do PIBID. As mudas começaram a brotar em setembro, e em final de outubro e novembro foi possível o consumo de verduras e legumes orgânicos. Concomitantemente à implantação da horta, foi construída uma composteira, descrita a seguir.

\section{A compostagem}

É uma prática que consiste basicamente em reaproveitar resíduo orgânico para gerar adubo, que é utilizado no desenvolvimento das plantas. Tendo em vista o grande volume de lixo gerado pelas grandes cidades, a compostagem pode ser uma solução. $O$ fato de armazenar lixo e não reciclá-lo demonstra de forma rápida que a quantidade de lixo produzida é insustentável para o planeta, e essa argumentação foi usada em campanha realizada pelos estudantes para a redução do consumo de modo geral, separação dos resíduos sólidos e preservação do solo, além de desviarem uma parte dos resíduos orgânicos para a compostagem feita na escola.

A composteira foi construída de baldes reciclados, que antes continham alimentos industrializados, ela contava com três recipientes, dois destinados à etapa digestora onde ocorria a compostagem dos resíduos orgânicos e um coletor de chorume com torneira, assim sendo um sistema de reciclagem dos resíduos orgânicos onde minhocas e microrganismos transformavam restos de alimentos em adubos.

Os dois recipientes digestores foram furados, no fundo, para facilitar o fluxo das minhocas e do chorume e, nas laterais, para aumentar a oxigenação do sistema digestor e aeração para os seres vivos. O recipiente coletor possuía uma torneira para 
facilitar a retirada do chorume, e esse produto era diluído em água e utilizado na irrigação da horta.

Os resíduos orgânicos eram colocados no balde digestor superior e, quando este estava completamente preenchido, ele era trocado de posição com o que estava no meio. Ao subir esse recipiente, o húmus e compostos presentes deveriam ser retirados para abrir espaço para a inserção de novos resíduos orgânicos. Essas operações eram realizadas pelos alunos, sob a orientação da professora de Ciências e dos bolsistas do PIBID-Ciências.

Esse instrumento representou um laboratório vivo, por permitir aos educadores mostrarem de forma prática, aos estudantes, a decomposição de matéria orgânica e os processos químicos e biológicos envolvidos na decomposição.

\section{Trabalhando a interdisciplinaridade}

No desenvolvimento do trabalho, considerou-se que a interdisciplinaridade:

[...] caracteriza-se pela intensidade das trocas entre os especialistas e pelo grau de integração real das disciplinas no interior de um mesmo projeto. A interdisciplinaridade visa à recuperação da unidade humana pela passagem de uma subjetividade para uma intersubjetividade e, assim sendo, recupera a ideia primeira de cultura (formação do homem total), o papel da escola (formação do homem inserido em sua realidade) e o papel do homem (agente das mudanças do mundo) (JAPIASSÚ 1976 apud THIESEN, 2008, p. 548).

Nesse sentido, o projeto horta escolar abrangeu diversas disciplinas e conteúdos, como:

- Ciências - a relação da cor do alimento com os seus nutrientes, por meio da atividade da cromatografia em papel; o processo da fotossíntese, por intermédio de um experimento na fase clara e escura.

- Língua Portuguesa - elaboração de relatórios, documentando observações como mudanças de plantas, 
condições meteorológicas e das atividades desenvolvidas na horta escolar.

- História/Ciências Sociais - diferenças culturais e/ou étnicas nos alimentos de consumo e de jardinagem, além das mudanças sofridas pela agricultura desde o seu surgimento, salientando sua vital importância para o desenvolvimento da humanidade em diversos aspectos.

- Matemática/Geometria - proporção para a diluição do chorume e sua utilização na horta; geometria para o uso dos espaços e construção dos canteiros; cálculo de área para a delimitação e proporcionalidade nos canteiros semeados.

- Artes - utilização dos pigmentos extraídos dos vegetais, por exemplo, a beterraba; estudo sobre a extração do pau-brasil para a utilização de seus pigmentos. Pigmentos que são usados em pinturas ou artesanato em geral.

Integrando diversas áreas do conhecimento, foi possível conscientizar os estudantes sobre questões científicas, de saúde e sociais relacionadas ao cultivo e consumo de alimentos, atrelados à preservação ambiental sustentável. Atualmente, com a industrialização de diversos tipos de produtos, inclusive os alimentícios, faz-se necessário um esclarecimento a respeito da procedência dos mesmos e como podemos mudar alguns hábitos utilizando alternativas simples, naturais, menos agressivas ao meio ambiente e à saúde.

O que se espera é que, apropriando-se dos conteúdos trabalhados, os educandos possam realizar escolhas alimentares mais saudáveis, aplicar o que foi aprendido em suas vidas cotidianas e reconhecerem o ambiente escolar não apenas como um transmissor de conteúdos teóricos.

\section{Prática e ação}

Durante todo o trabalho, foi visado o desenvolvimento de habilidades e atitudes como cooperação e autonomia, por meio de trabalho em equipe, organização e planejamento, relacionando teoria e prática constantemente. A criação da horta escolar foi muito além do plantio, significou a construção de 
muitos conhecimentos, a valorização de recursos naturais, além da tentativa de superação do desperdício alimentar e se tornou motivo de diálogo, interação, troca e participação de alunos, pais, educadores, funcionários e comunidades, inclusive difundindo os novos conhecimentos. Todos tenderam a ser agricultores, a aprender e ensinar juntos, valorizando a descoberta do poder de transformação da terra com as próprias mãos. Afinal,

[...] o ensino de Ciências pode e deve partir de atividades problematizadoras, cujas temáticas sejam capazes de relacionar e conciliar diferentes áreas e esferas da vida de todos nós, ambicionando olhar para as ciências e seus produtos como elementos presentes em nosso dia-a-dia e que, portanto, apresentam estreita relação com nossa vida (SASSERON \& CARVALHO, 2011, p. 66).

A horta desenvolveu a aprendizagem e oportunidades sensoriais, incentivando todos a se envolverem com o cultivar de seus próprios alimentos, proporcionando um ambiente que maximizava a produção de alimentos. Os estudantes tiveram a oportunidade de atingir as metas especificadas em seus planos de atividades em grupo e individuais, trabalhando e realizando atividades relacionadas à horta, que proporcionaram diferentes aprendizagens e promoveram a troca de conhecimentos entre a escola e a família.

\section{Aspectos do trabalho por projetos}

No desenvolvimento do projeto, observou-se a intensidade das relações de trabalho, a importância do princípio de autogestão, a busca do estudante autônomo, trabalhando em uma organização horizontal onde não há hierarquia entre os sujeitos, e a valorização da aprendizagem significativa, conforme afirma Leite (1996):

A pedagogia de projetos se coloca como uma das expressões dessa concepção globalizante que permite aos alunos analisar os problemas, as situações e os acontecimentos 
dentro de um contexto e em sua globalidade, utilizando, para isso, os conhecimentos presentes nas disciplinas e sua experiência sociocultural (p. 29).

Em pequenas tarefas, foram difundidos princípios de participação com enfoque na cooperação e formação do sujeito autônomo, feliz, preocupado com a realização do trabalho na busca pela melhoria da comunidade e não ao sujeito isolado, mas pensando no coletivo e conduzindo processos democráticos. $\mathrm{O}$ projeto da horta teve caráter social, mas também teve caráter de investigação e experimentação, e todos contribuíram para o desenvolvimento integral do estudante.

\section{CONSIDERAÇÕES FINAIS}

A sustentabilidade não se reduz à simples elaboração de programas sustentáveis, mas passa pela contínua discussão sobre a maneira de formar estudantes engajados com suas relações sociais, com o meio ambiente e com a comunidade, em diferentes escalas. Tal discussão se relaciona com a formação do sujeito, sua representação social e a relação com a comunidade inserida. Daí a importância de buscar continuamente a formação do sujeito político participativo e sensível frente a problemas socioambientais. Faz-se impossível tornar escolas realmente sustentáveis sem que haja participação democrática de toda a comunidade. Contudo, é necessário utilizar novos modelos de ensino e relações socioescolares que direcionem para o enfrentamento da crise na educação e na sociedade.

O projeto da horta escolar desenvolveu uma melhor interação entre professores e estudantes, cultivando atitudes voltadas para a preservação, conservação do meio ambiente e alimentação saudável.

Embora a alimentação servida nas escolas dificilmente seja enxergada como conteúdo de ensino, ou material para estudos, segundo Magalhães e Gazola (2002), a educação alimentar precisa ser impelida para o ambiente escolar, onde o aluno pode e necessita reforçar a adoção de boas condutas alimentares. E o trabalho com a horta foi uma ferramenta para isso. 
Portanto, acredita-se que a construção da horta pode contribuir de forma direta na alimentação dos estudantes, e também no desenvolvimento de habilidades e técnicas de manejo sustentável. O cultivo dos alimentos no ambiente escolar se faz livre de agrotóxicos, com a utilização dos resíduos orgânicos produzidos na própria escola, e esse cultivo pode ser auxiliado pela construção de uma composteira.

Esses projetos são tidos como de fácil viabilização, pois as escolas geram resíduos sólidos orgânicos, que são restos do preparo dos alimentos e sobras das refeições, que podem ser utilizados para a compostagem, utilizados nas hortas e jardins escolares, por exemplo.

A proposta dessas atividades tem diversas intenções no ensino. Entre elas, pode-se elencar: a melhora da dinâmica das aulas e o desenvolvimento de projetos e iniciativas em outras disciplinas, transformando-se em um espaço interdisciplinar e de inclusão social.

Justificando então a necessidade da construção de uma horta na escola, esta auxiliará na vivência com diferentes tipos de vegetais, de forma simples e contextualizada, o que possibilita maior qualidade no ensino, em via de melhorar o trânsito do conhecimento escola-comunidade.

A participação desses estudantes como protagonistas do projeto e o incentivo à mobilização rumo à multiplicação das práticas sustentáveis é um dos primeiros passos para a construção de um processo educativo articulado com os processos de mudança social e prática de cidadania.

Trabalhar com ações desse tipo permite aos educandos, como sujeitos, participarem ativamente na sociedade e estar à margem do conhecimento científico, e desenvolver capacidades científicas que lhes permitam estender o pensamento crítico em relação às questões sociais e político-ambientais. Esses parâmetros são marcos do desenvolvimento de uma cultura científica, por desenvolver atitudes, capacidades científico-críticas, que permitem a inserção desses estudantes sujeitos na sociedade do conhecimento, e contribuem para a melhora da qualidade de vida no contexto de uma cultura científico-tecnológica. 


\section{REFERÊNCIAS}

BRASIL. Ministério da Educação. Secretaria de Ensino Fundamental. Parâmetros curriculares nacionais: apresentação dos temas transversais. Brasília: MEC/SEF, 1998.

COSTA, A. P. da; SILVA, W. C. M. A Importância da Compostagem em Aulas Práticas de Ciências Naturais E Geografia na Escola Municipal Maria Cândido de Oliveira em Cachoeira dos Índios - PB. In: $6^{\mathbf{a}}$ Reunião Anual da SBPC, 2011.

GADOTTI, Moacir. Boniteza de um sonho: ensinar-e-aprender com sentido. Novo Hamburgo: Feevale, 2003.

KILPATRICK, W. H. Educação para uma civilização em mudança. São Paulo: Melhoramentos, 1967.

LEITE. Pedagogia de projetos: Intervenção no presente. Presença pedagógica, 1996, n. 8, p. 24-33.

MAgAlHÃES, A. M.; GAZOLA H. Proposta de Educação Alimentar em Creches. Congresso Internacional de Educação Infantil. 1. Bombinhas, 2002. Anais... Bombinhas: PMPB, 2002.

MORAN, J. M.; MASETTO, M. T.; BEHRENS, M. A. Novas tecnologias e mediação pedagógica, 3. ed. Campinas: Papirus, 2001.

MORGADO, F. S.; SANTOS, M. A. A. A Horta Escolar na Educação Ambiental e Alimentar: Experiência do Projeto Horta Viva nas Escolas Municipais de Florianópolis. EXTENSIO: Revista Eletrônica de Extensão, Santa Catarina, n. 6, 2008.

PRADO, M. E. B. B. Pedagogia de projetos: fundamentos e implicações. In: ALMEIDA, M. E. B. de; MORAN, J. M. (Org.). Integração das tecnologias na educação. Brasília: Ministério da Educação/SEED/TV Escola/Salto para o Futuro, 2005, cap. 1, artigo 1.1, p. 12-17.

SASSERON, L. H. \& CARVALHO, A. M. P. Alfabetização científica: Uma revisão bibliográfica. Investigações em Ensino de Ciências, v. 16, p. 59-77, 2011. THIESEN, J. S. A interdisciplinaridade como um movimento articulador no processo ensino-aprendizagem. Rev. Bras. Educ. Rio de Janeiro, v. 13, n. 39, p. 545-554, dez. 2008.

TURANO, W. A Didática na Educação Nutricional. In: GOUVEIA, E. Nutrição Saúde e Comunidade. São Paulo: Revinter, 1990.

ZUCCHI, O. J. Educação Ambiental e os Parâmetros Curriculares Nacionais: Um estudo de caso das concepções e práticas dos professores do ensino fundamental e médio em Toledo-Paraná. Dissertação (Mestrado em Engenharia de Produção), UFSC, Florianópolis, 2002. 


\section{SOBRE AS AUTORAS}

Priscila Toscano Lima é Mestranda no Programa de Pós-Graduação em Ensino de Ciências e Matemática/UNIFESP e professora da Escola Estadual Padre Anchieta em Diadema/SP - pri_toscano@yahoo.com.br

Natália Dias é Mestranda no Programa de Pós-Graduação em Ensino de Ciências e Matemática/UNIFESP - natalia.fdias@outlook.com

Marilena Rosalen é Professora do Programa de Pós-Graduação em Ensino de Ciências e Matemática/UNIFESP - marilena.rosalen@gmail.com 